\title{
Avaliação Cognitiva de Leitura e Escrita: As Tarefas de Leitura em Voz Alta e Ditado
}

\author{
Angela Maria Vieira Pinbeiro ${ }^{1}$ \\ Rui Rothe-Neves \\ Universidade Federal de Minas Gerais
}

\begin{abstract}
Resumo
Tarefas de leitura em voz alta e de tomada de ditado de listas de palavra reais e de não-palavras, isoladas, fazem parte de um conjunto de provas maior - o Procedimento de Avaliação Cognitiva da Leitura e da Escrita. Com base em Seymour, Pinheiro desenvolveu um teste experimental que se mostrou adequado para avaliação de leitura e de escrita em crianças mineiras da primeira à quarta série do Ensino Fundamental. O procedimento foi retestado, com sucesso, por Capovilla, Capovilla e Macedo. A partir desses resultados, Pinheiro desenvolve, atualmente, um instrumento computadorizado de avaliação que consiste de tarefas de leitura em voz alta e de tomada de ditado, entre outras. O presente trabalho discute as bases teóricas para a construção das listas de palavras reais e de não-palavras, com ênfase no controle da variável regularidade letra-som/som-letra. Palavras-chave: Avaliação cognitiva; leitura; escrita; regularidade.
\end{abstract}

\section{Cognitive Assessment of Reading and Writing: Reading-Aloud and Spelling Tasks}

\begin{abstract}
Reading-aloud and spelling tasks using single word and nonword lists are part of a broader set of tests called Cognitive Assessment Procedure. Based on Seymour, Pinheiro developed an experimental test which seemed suitable for reading and writing assessment of first to fourth graders in Minas Gerais. That procedure was retested by Capovilla, Capovilla and Macedo. Based on those results, Pinheiro is presently involved in developing a computerized assessment procedure, which includes reading-aloud and spelling tasks, among others. This article presents the theoretical basis for the construction of single word and nonword lists, emphasizing the control of letter-sound/sound-letter regularity effect.

Keywords: Cognitive assessment; reading; writing; regularity.
\end{abstract}

A avaliação das rotas lexical e fonológica do modelo de processamento da leitura e da escrita (Ellis \& Young, 1988; Lecours, Delgado \& Parente, 1983; Seymour, 1986)² é feita por meio de tarefas de leitura em voz alta. Essas tarefas consistem de experimentos em que se apresentam aos sujeitos, ora uma lista de palavras reais, ora uma de não-palavras, sendo-lhes solicitado que leiam em voz alta os itens de cada lista (um de cada vez), o mais rápido e corretamente possível. Medidas de tempo de reação (TR) de emissão de pronúncia e/ou de taxas de precisão são registradas. Alternativamente, as palavras reais e as nãopalavras são apresentadas juntas em uma mesma lista. Esse é o procedimento adotado por Capovilla, Capovilla e Macedo (1998), com crianças, e por Parente, Hosogi e Lecours (1997) com adultos portadores de dislexia

\footnotetext{
${ }^{1}$ Endereço para correspondência: Departamento de Psicologia, Faculdade de Filosofia e Ciências Humanas, FAFICH, Universidade Federal de Minas Gerais. Av. Antonio Carlos, 6627, Pampulha, 31260-901, Belo Horizonte, MG. Fone: (31) 4995022, Fax: (31) 4995027.E-mail: apinheir@fafich.ufmg.br 2 Aqui, será utilizada a terminologia de Ellis e Young (1988).
}

adquirida. O presente trabalho discute as bases teóricas para a construção das listas de palavras reais e de nãopalavras, com ênfase no controle da variável regularidade letra-som/som-letra.

Os componentes de um sistema de processamento de informação podem ser investigados por meio da manipulação sistemática de fatores que se considera exercerem uma influência seletiva em um processo particular, como será demonstrado. Do ponto de vista do modelo adotado, o processo de ler qualquer estímulo em voz alta depende da análise do item (palavra real ou não-palavra), no sistema de análise visual. $\mathrm{Na}$ leitura de palavras reais, após serem reconhecidas no léxico visual de entrada, a pronúncia é recuperada do léxico fonêmico de saída (o que constitui a rota léxico-fonêmica). Esse processo de recuperação pode ser assistido por concomitante processamento semântico ou por concomitante conversão grafema-fonema. No caso das não-palavras, a identidade dos grafemas é transmitida do sistema de análise visual para o sistema de conversão grafema-fonema, onde os elementos fonêmicos podem 
ser recuperados e sintetizados (ou agrupados) para produzir a pronúncia (rota fonológica). Assim, a leitura de palavras é um teste da rota lexical e a de não-palavras, um teste do processo fonológico.

$\mathrm{Na}$ escrita, como na leitura, também o lado lexical tem sido investigado por meio do uso de palavras reais, e o lado fonológico, pelo uso de não-palavras. Ambos os tipos de estímulos são ditados (tarefas de tomada de ditado). Os efeitos obtidos (tanto em TR como em níveis de erros na leitura, e apenas em níveis de erros na escrita) são, então, tomados como base para inferências sobre as propriedades do processamento de um determinado sistema.

Os fatores geralmente manipulados na tarefa de leitura em voz alta/ditado de palavras reais têm a finalidade de oferecer informação sobre o seguinte: (1) efeitos de variação do número de letras (efeito de comprimento) na leitura, (2) efeitos de variação dos níveis de familiaridade de palavras sobre a leitura e a escrita (efeito de freqüência), (3) o envolvimento do processo semântico na leitura e na escrita, e (4) o envolvimento do processo de conversão grafema-fonema na recuperação da pronúncia, na leitura, ou do processo de conversão fonema-grafema na produção da grafia de uma palavra escrita. Por limites de espaço, lidaremos aqui apenas com os pontos (2) e (4), que se referem ao efeito de freqüência e o efeito de regularidade, respectivamente.

O efeito de variações nos níveis de familiaridade de palavras - fator freqüência de ocorrência de palavras tem sido visto como tendo uma influência nas funções da rota léxico-fonêmica, que pode dar-se no nível de reconhecimento (no léxico visual de entrada) ou na operação de recuperação lexical da pronúncia (léxico fonêmico de saída), na leitura, ou no nível de produção (léxico grafêmico de saída), na escrita. As palavras de alta freqüência, por requererem menor ativação, tendem a ser reconhecidas/produzidas mais rapidamente e/ou mais corretamente do que aquelas com baixa ocorrência - palavras de baixa freqüência. Essa vantagem em termos de processamento, para o primeiro tipo de palavras, é conhecida como efeito de freqüência. Assim, a ocorrência desse efeito é interpretada como uma indicação do envolvimento do processo lexical na leitura em voz alta e na escrita, enquanto um efeito de freqüência exagerado (maior do que normalmente encontrado), por sua vez, indica um nível de disfunção do processo lexical.

A variação do fator regularidade grafema-fonema (leitura) ou fonema-grafema (escrita) tem demonstrado que o processamento pela rota fonológica é afetado adversamente pela regularidade do estímulo. Isso ocorre porque o sistema de conversão grafema-fonema (ou fonema-grafema), por interpretar o input em termos das correspondências regulares, pode produzir uma representação fonológica (ou grafia) incorreta para uma palavra irregular, que algumas vezes será regularizada (p. ex.: a palavra irregular boxe, lida como boche e escrita como boquise). Na leitura, essa pronúncia regularizada pode entrar em conflito com a pronúncia correta, produzida pela rota lexical. A resolução desse impasse requer uma consulta ao léxico para uma confirmação, o que acarreta um atraso no tempo de reação. Em conseqüência, quando ocorre um efeito de regularidade, ele é tomado como indicação de que houve algum processamento fonológico na recuperação da pronúncia (ou produção da grafia) para uma palavra.

A natureza do funcionamento da rota lexical é determinada pelo exame do impacto da variável freqüência de ocorrência e regularidade sobre o tempo de processamento e número de erros. Uma abolição total do processo lexical é indicada quando somente as palavras regulares em cada nível de freqüência são lidas/grafadas corretamente. No entanto, a situação em que algumas palavras irregulares de alta freqüência são lidas/grafadas corretamente indica uma certa preservação do processo lexical e que os itens de baixa freqüência são os mais vulneráveis. As palavras pouco familiares, que não podem ser reconhecidas, são, em conseqüência, processadas pela rota fonológica. Isso gera, como vimos, erros de regularização, além de erros de acentuação tônica (Seymour, 1986).

Nos experimentos de leitura em voz alta de nãopalavras, por outro lado, as não-palavras são construídas com a mesma estrutura ortográfica e mesmo comprimento das palavras reais ${ }^{3}$. O contraste entre o desempenho na leitura/escrita de palavras reais e de nãopalavras é conhecido como efeito de lexicalidade. Esperase que as palavras reais, por terem representações ortográficas, semânticas e fonológicas pré-estocadas no léxico, sejam lidas/grafadas mais rápida e corretamente do que as não-palavras, cuja pronúncia/grafia (não existente no léxico) é construída na rota fonológica, por meio de decodificação grafema-fonema (leitura) e fonema-grafema (escrita). Como palavras reais e nãopalavras podem ser lidas/grafadas pela rota fonológica, mas apenas as palavras reais podem ser lidas/grafadas pela rota lexical, o efeito de lexicalidade (a vantagem das palavras reais em relação às não-palavras) sugere uso do processo lexical. No entanto, um forte efeito de lexicalidade, ou seja, leitura/escrita de não-palavras, bem

\footnotetext{
${ }^{3}$ Um outro fator que pode ser controlado nesses experimentos refere-se à pronúncia de não-palavras que soam como palavras reais (p. ex.: táquissi que soa como táxi) ou daquelas que não soam com tais (p. ex.: sali) - efeito de homofonia .
} 
mais lenta do que a de palavras reais, indica uma deficiência no processo fonológico.

\section{Medidas nas Tarefas de Leitura em Voz Alta e Ditado em Crianças}

Em várias publicações (p. ex.: Seymour, 1986, 1987; Seymour \& MacGregor, 1984), Seymour desenvolveu um método para a investigação dos processos básicos de leitura, que recebeu a denominação de Procedimento de Avaliação Cognitiva. Esse método, que atualmente constitui referência para a construção de conjuntos semelhantes de procedimentos em diferentes línguas alfabéticas, consiste no uso de tarefas de leitura em voz alta de palavras reais e de não-palavras, e de tarefas de decisão sobre a propriedade visual, lexical ou semântica de um estímulo. Discutiremos aqui apenas as primeiras tarefas, no âmbito de uma revisão de trabalhos que as utilizaram no Brasil (as tarefas de decisão ainda não foram testadas com crianças brasileiras).

\section{O Trabalho de Pinheiro}

Pinheiro (1994, 1995), em uma investigação sobre a evolução dos processos de leitura e de escrita em crianças mineiras da primeira à quarta série do Ensino Fundamental, desenvolveu um teste experimental de reconhecimento (leitura) e de produção (escrita) de palavras reais e de nãopalavras, baseado nas tarefas de leitura em voz alta de Seymour (op. cit.). Esse instrumento mostrou-se adequado para a avaliação do comportamento de leitura/escrita das crianças estudadas e enfatizou o ponto no desenvolvimento em que os processos fonológico e lexical emergem, e quando predominam no desenvolvimento. Além disso, distinguiu o desempenho dessas crianças do de um segundo grupo, também cursando as séries iniciais do ensino fundamental, que apresentava dificuldades na aquisição da leitura e da escrita.

O teste de Pinheiro é formado por um total de 96 palavras reais (PRs) e de 96 não-palavras (NPs). As PRs variam em freqüência de ocorrência, em regularidade ortográfica e em comprimento. As NPs variam em comprimento (4-7 letras) e foram construídas com a mesma estrutura ortográfica e o mesmo comprimento dos estímulos usados nas listas de PRs.

A classificação de regularidade considerou principalmente as irregularidades do português brasileiro, que são importantes para a escrita e consistiu na distinção de três categorias de estímulos: (1) regular (R), aquelas que têm uma relação unívoca entre fonema e grafema (p. ex.: vila, porta, papai); (2) regular, dependente de contexto, quando é preciso aplicar regras de contexto ortográfico para se obter uma relação unívoca entre grafema e fonema (aqui denominada regra - (RG)) (p. ex.: casa, usam, porão); e, (3) irregular (I), quando a relação fonema-grafema e entre o grafema e o seu som é irregular, ou seja específica de uma determinada palavra (p. ex.: hino, açude, xerife). A classificação de freqüência de ocorrência implicou na distinção de palavras nas categorias de alta freqüência (AF) e de baixa freqüência (BF) (Pinheiro \& Keys, 1987). As não-palavras mantiveram as correspondências regular, regra e irregular das palavras, das quais elas foram derivadas. Por exemplo, o estímulo dasa derivado de casa, como o próprio estímulo casa, foi classificado como regra. Da mesma forma eçute, derivado de açude foi tomado como irregular.

As análises estatísticas, conduzidas em nível individual, consistiram na procura de efeitos lingüísticos (efeito de freqüência, de regularidade ortográfica e lexical), e procedimentais (efeito de comprimento) nos tempos de reação, e de efeitos lingüísticos apenas nas porcentagens de $\operatorname{erros}^{4}$. Os tempos de reação foram comparados por teste $t$ e as porcentagens de erros por $\chi^{2}$. Independentemente do tipo e do número de erros cometidos em um mesmo item, somente um erro foi marcado para aquele item. As médias dos sujeitos, a cada nível escolar, foram comparadas por análise de variância, com medidas repetidas. Os fatores intrasujeito foram freqüência, regularidade, comprimento e lexicalidade e o fator inter-sujeito foi a série escolar. Foram feitas tanto as análises de sujeito como as de itens.

\section{O Trabalho de Capovilla e colaboradores}

Capovilla e colaboradores (1998) replicaram os resultados de Pinheiro (1994, 1995) em uma amostra de 122 crianças paulistas cursando da primeira à terceira série do Ensino Fundamental. As crianças leram, individualmente, 189 dos 192 itens das listas de Pinheiro em uma única sessão. Os dados obtidos foram analisados com relação a três medidas: (1) tempo de reação locucional, (2) duração locucional e (3) padrão de segmentação. Pinheiro controlou apenas a primeira medida. Os dados de Capovilla e colaboradores corresponderam bem aos resultados de Pinheiro. Em ambos os estudos, e de acordo com a literatura, foram encontrados os efeitos de freqüência, regularidade, comprimento e lexicalidade. Por exemplo, os efeitos de freqüência e lexicalidade obtidos na leitura/escrita (Pinheiro) e leitura (Capovilla \& cols.) em todas as séries estudadas sugere o uso do processo lexical para a leitura/escrita de estímulos familiares e do uso do processo fonológico para ler/escrever estímulos não-familiares.

Uma diferença entre o estudo de Pinheiro $(1994,1995)$ e o de Capovilla e colaboradores (1998) é que, no primeiro estudo, em cada condição, efetuou-se análises estatísticas

\footnotetext{
${ }^{4}$ A análise de erros não considerou o efeito de comprimento.
} 
tanto nas médias dos sujeitos como nas médias dos estímulos (itens), ou seja, análise de sujeito e de itens, respectivamente, segundo recomendação de Clark $(1973)^{5}$. Assim, a ocorrência de um efeito foi considerada apenas quando se obteve resultados significativos em ambas as análises. A implicação dessa diferença de procedimento refere-se especificamente ao efeito de regularidade na leitura. Tal como Capovilla e colaboradores, Pinheiro encontrou, para palavras reais e não-palavras, quase exatamente os mesmos efeitos principais e interações envolvendo a variável regularidade. No entanto, a análise de itens confirmou apenas a diferença em tempo de processamento para as palavras regulares de baixa freqüência versus palavras irregulares de baixa freqüência, para a primeira e segunda série. Com base nisso, Pinheiro concluiu que as diferentes categorias de regularidade somente tiveram um efeito significativo na leitura de palavras de baixa freqüência e que esse efeito (palavras regulares lidas mais rapidamente do que palavras irregulares) foi restrito ao tempo de processamento e aos anos iniciais (primeira e segunda série), não se estendendo aos erros cometidos.

Esses resultados indicam que o efeito de regularidade para palavras reais (exceto nas análises confirmadas) e não-palavras não pode ser generalizado para a população de itens e que deve ser atribuído apenas a alguns dos itens testados. Tomando a análise de erros, por exemplo, é curioso notar que apenas os estímulos cobras (BF/R), facão (BF/RG), boxe, peço e ouça (todos BF/I) apresentaram altos índices de erros na leitura (acima de 10 erros em uma amplitude de 0-33 erros por item para os sujeitos da primeira à quarta série). Dentre esses, somente o estímulo boxe causou regularizações ${ }^{6}$.

Os resultados encontrados sugerem que a leitura fonológica predomina no início da alfabetização. Por volta

\footnotetext{
${ }^{5}$ Segundo Clark (1973), para que os resultados dos experimentos que usam materiais lingüísticos como estímulo possam ser generalizados deve-se usar além da análise de sujeito, a análise de itens. Uma generalização só pode ser feita mediante a obtenção de resultados significativos em ambas as análises.

Enquanto boxe /'bokse/ foi pronunciado predominantemente como boche /'bose/, peço/'peso/ foi lido por alguns como "peso" /'pezo/ (o grafema $<c ̧>$ parece ter sido trocado pelo grafema $<\mathrm{s}>$, que no contexto intervocálico se realiza como /z/) e por outros como /'peso/ (a qualidade da vogal $\langle\mathrm{e}\rangle$ foi trocada de aberta para fechada). Já o estímulo facão foi lido pela maioria dos sujeitos como "fação" /'fasãwN/ (a regra fonológica que diz que o som [k] é grafado pela letra $<\mathrm{c}>$ antes de $<\mathrm{a}>$ ou $<\mathrm{u}>$ não foi levada em conta). Finalmente os estímulos cobras e ouça, foram lidos, como cobra e onça, respectivamente, que mais parece erros de troca visual de letras do que lexicalizações. Temos então que em cada categoria de regularidade algumas palavras, em especial, foram fontes de erros e que esses erros foram indicativos tanto de leitura fonológica (regularizações, erros de troca da qualidade da vogal e erros contextuais) como de leitura lexical (lexicalizações).
}

da terceira série, quando as crianças estão desenvolvendo representações lexicais para os itens menos familiares, o efeito de regularidade tende a desaparecer. No entanto, devemos considerar essa interpretação com cautela, principalmente porque, em português, a maioria das palavras irregulares para a escrita pode ser pronunciada com o uso das regras de correspondência letra-som. É possível que as crianças mais experientes, por terem um maior conhecimento dessas regras, não mostrem o efeito de regularidade. Assim, a lista de Pinheiro (1994, 1995), cuja classificação de regularidade foi feita com base na escrita, pode ter induzido à ausência do efeito de regularidade na leitura das crianças mais experientes, impedindo-nos, pois, de avaliar com precisão a emergência do processo lexical na leitura. Essa possibilidade tem implicações para a construção de novas listas.

Por outro lado, na escrita e ainda no estudo de Pinheiro (1994, 1995), a variável regularidade apresentou um efeito significativo para as palavras reais. Em cada série, as palavras irregulares produziram mais erros do que as palavras regra, e estas, por sua vez, mais erros do que as palavras regulares, em ambos os níveis de freqüência. Esse efeito foi significativo tanto na análise de sujeito como na de itens em cada série, separadamente, e aplicou-se tanto às palavras de alta freqüência como as de baixa freqüência. Um efeito geral de regularidade foi também encontrado para as não-palavras.

\section{Discussão}

Esses resultados indicam que, em português, como em muitos outros alfabetos, a variável regularidade pode ter implicações muito maiores para a escrita - cujas regras são mais complexas e em número bem mais reduzido do que para a leitura. Em segundo lugar, levantam a questão sobre se a classificação tanto de palavras reais como de não-palavras em níveis de regularidade, faz sentido para a leitura em português. A seguir, discutimos essas questões do ponto de vista de suas implicações para futuros estudos.

\section{A Variável Regularidade de Palavras é Importante na Leitura?}

Em nosso idioma, a relação grafema-fonema pode, em grande parte, ser expressa por regras. As exceções são o grafema $<\mathrm{x}>$ entre vogais (nesse contexto, o $<\mathrm{x}>$ pode valer $\left[\int, \mathrm{z}, \mathrm{s}, \mathrm{ks}\right]$ ou $[\varnothing]$ como em vexame, exame, trouxe, táxi e exceto, respectivamente) e os vocálicos $<_{\mathrm{O}}>$ e $<\mathrm{e}>$ em posição paroxítona (p. ex.: cedo/ 'cedw/, seca / 'sckə/, nono /'nonw/, copo /'kəpw/) cuja pronúncia, aberta 
ou fechada, é determinada lexicalmente. Palavras contendo esses sons vocálicos estão sujeitas a erros de troca de qualidade (aberta para fechada e vice-versa) de vogal, quando lidas pela via fonológica.

Enquanto o grafema $<\mathrm{x}>$ é irregular tanto para a leitura como para a escrita, as vogais $<_{\mathrm{O}}>\mathrm{e}<\mathrm{e}>$ não causam dificuldade na escrita: tanto /e/ e / $/$ /, como /o/ e / o/ serão sempre grafados com as letras $<_{\mathrm{e}}>_{\text {ou }}<_{\mathrm{O}}>_{\text {. Assim, }}$ segundo Parente, Silveira e Lecours (1997), torna-se necessário distinguir esses dois tipos de irregularidade grafema-fonema em: (1) palavras irregulares para a leitura e escrita - palavras contendo o intervocálico $<\mathrm{x}>$ (irregularidade do tipo 1A) e (2) palavras irregulares apenas para a leitura - palavras contendo os vocálicos $<_{\mathrm{O}}>$ ou $<\mathrm{e}>$ em posição paroxítona (irregularidade do tipo 1B). Considerando que o número de palavras tipo $1 \mathrm{~A}$ é bem

Tabela 1. Exemplos de Irregularidade Tipo 1B (Vogais $<_{\mathrm{O}}>\mathrm{e}<\mathrm{e}>$ em Posição Paroxítona)

\begin{tabular}{|c|c|c|c|c|c|}
\hline \multicolumn{3}{|c|}{ Alta Freqüência } & \multicolumn{3}{|c|}{ Baixa Freqüência } \\
\hline Regular & Regra & Irregular & Regular & Regra & Irregular \\
\hline colegas & escreva & cabeça & chupeta & marreca & certos \\
\hline festa & & cedo & moeda & hora & peço \\
\hline folhas & & texto & mostra & quietos & tigela \\
\hline letra & & & pesca & & \\
\hline porta & & & seda & & \\
\hline
\end{tabular}

*Fonte: Pinheiro (1994).

Tabela 2. Estímulos Derivados de um universo de 278 palavras (palavras de baixa freqüência com irregularidade tipo 1B e comuns ao $V \backslash$ vocabulário de crianças da primeira a quarta série do ensino fundamental) que causaram erros de troca de qualidade de vogal na leitura de 20 crianças de segunda série

\begin{tabular}{ll}
\hline Palavras & Porcentagem \\
\hline ampola & $45(09 / 20)^{*}$ \\
novelo & $45(09 / 20)$ \\
fera & $40(08 / 20)$ \\
nono & $40(08 / 20)$ \\
cometa & $35(07 / 20)$ \\
fossa & $35(07 / 20)$ \\
besta & $30(06 / 20)$ \\
bobo & $30(06 / 20)$ \\
foco & $30(06 / 20)$ \\
negra & $30(06 / 20)$ \\
rolha & $30(06 / 20)$ \\
roxa & $30(06 / 20)$ \\
berro & $25(05 / 20)$ \\
casebre & $25(05 / 20)$ \\
cera & $25(05 / 20)$ \\
cova & $25(05 / 20)$ \\
cloro & $25(05 / 20)$ \\
exposto & $25(05 / 20)$ \\
gesso & $25(05 / 20)$ \\
\hline Entre parênteses, número de crianças, num total de 20, que cometeram erros de troca de qualidade de vogal
\end{tabular}

Psicologia: Reflexão e Crítica, 2001, 14(2), pp. 399-408 
Em função desses resultados, no estudo exploratório de Oliveira, Carvalho e Yoshihara (2000), um grupo de 20 crianças de segunda série leu uma lista com 278 palavras de baixa freqüência, com irregularidade tipo 1B, com o objetivo de identificar os estímulos que iriam favorecer erros de troca de qualidade de vogal que, como vimos, é um sinal de leitura fonológica. Mediu-se, nesse estudo, apenas as taxas de erros. Como antecipado, descobriu-se que, do total de palavras lidas, apenas dezenove $(6,83 \%)$ causaram erros de troca de qualidade de vogal. Dentre essas palavras, apenas alguns poucos estímulos apresentaram altos índices de erros (Tabela 2). Considerando que a leitura fonológica ainda é bem acentuada na segunda série, e que só palavras de baixa freqüência foram testadas, podemos concluir que a única irregularidade da relação letra-som do português, exclusiva da leitura, parece ter limitações como teste do processo usado na leitura.

No estudo de Oliveira e colaboradores (2000) as palavras irregulares não foram emparelhadas com palavras regulares. Assim, como alertam Parente e colaboradores (1997), os erros observados podem estar refletindo uma dificuldade de leitura de palavras pouco freqüentes, e não um efeito de regularidade. Com o objetivo de investigar de forma mais adequada que palavras com irregularidade tipo $1 \mathrm{~B}$ estão sujeitas a erros de troca de qualidade de vogal (ou a aumentos de tempo de reação) e de estabelecer em que ponto do desenvolvimento esses erros predominam e declinam, o grupo de Pinheiro conduzirá um estudo em que listas formadas de palavras retiradas do universo original de 278 palavras, com seus respectivos controles, serão apresentadas a grupos de crianças da primeira à quarta série do ensino fundamental para serem lidas. Medidas de tempo de reação e de erros serão coletadas.

\section{Implicações dos Limites Impostos pela Variável Regularidade para a Construção de Novas Listas}

Como vimos, em português, como em muitos outros alfabetos não-regulares, o ato de ler é governado, com poucas exceções, por regras. Isso nem sempre ocorre na escrita. Embora na escrita haja também regras, essas são mais complexas e em número bem mais reduzido. A implicação dessa diferença é que, enquanto uma palavra pode ser regular do ponto de vista da leitura (p. ex.: criança, feliz, harpa), ela pode ser irregular para a escrita. Tendo em vista essa diferença entre a leitura e a escrita, Parente, Hosogi e Lecours (1997) sugerem que listas separadas para a leitura e para a escrita sejam usadas em uma conduta clínica para a avaliação da dislexia adquirida. A essas listas acrescentam uma outra, formada por palavras estrangeiras comuns e utilizadas com freqüência na nossa escrita (p. ex.: pizza, diet, coke). O objetivo dessa lista é favorecer a ocorrência de regularizações, já que nossa língua, possui poucas palavras com a letra $<\mathrm{x}>$. A lista de palavras para a leitura deve ser formada de palavras com irregularidade tipo 1 (palavras com grafema $<\mathrm{x}>$ entre vogais e os vocálicos $\left.<_{\mathrm{O}}\right\rangle_{\text {e }}<\mathrm{e}>$ em posição paroxítona) e a lista de palavras para o ditado, de palavras irregulares apenas para a escrita - palavras irregulares tipo 2 (excluindo-se os sons relacionados ao grafema $<\mathrm{x}>$ por serem irregulares tanto para a leitura como para a escrita). As palavras irregulares das duas listas devem ser emparelhadas com palavras regulares com a mesma extensão, freqüência, estrutura silábica e imageabilidade das palavras irregulares. Ambas as listas são lidas e ditadas para eventuais comparações entre a leitura e a escrita.

A princípio, para a avaliação do desenvolvimento dos processos lexical e fonológico (e de seus distúrbios) em crianças, parece fazer sentido adotar o mesmo procedimento usado por Parente e colaboradores (1997) para o diagnóstico da dislexia adquirida. Assim, na lista para a leitura, as palavras seriam classificadas do ponto de vista da correspondência letra-som como regular e irregular. Na primeira categoria estariam incluídas palavras com relação grafema-fonema unívoca (p. ex.: vida, haste, laço, feliz) e relação grafema-fonema também unívoca, mas dependente de contexto (p. ex.: cala/ cidade, gato/jipe, carrol caro) e na segunda categoria, palavras com irregularidade tipo 1 (p. ex.: fixo, novelo, escola). Na escrita, como na leitura, seriam regulares as palavras contendo correspondências fonema-grafema unívocas (p. ex.: vida, marca, fruta) e as palavras contendo correspondências unívocas, mas dependentes de regras contextuais (p. ex.: noite, facão, queda). Finalmente seriam consideradas como irregulares as palavras contendo relação fonema-grafema irregulares (palavras do tipo 2 - p. ex.: sela, cebola, gente).

No entanto, ao adotarmos esse procedimento, podemos nos deparar com o problema citado acima, em que levantamos a possibilidade da ausência do efeito de regularidade na leitura das crianças mais experientes no estudo de Pinheiro (1995) ser decorrente do domínio mais amplo, por essas crianças, das regras de correspondência letra-som. Assim, os estímulos criança, feliz e harpa, embora regulares na leitura, podem causar vagareza e/ou erros na leitura das crianças mais novas, que ainda não dominam bem todas as correspondências letra-som (principalmente as mais infreqüentes e irregulares na escrita). Deve ter sido por esse motivo que Pinheiro encontrou o efeito de regularidade na leitura das crianças mais novas. 
Considerando também as poucas irregularidades do português para a leitura, a maneira de resolver esse impasse seria construir listas em que as palavras seriam regulares e irregulares tanto para a leitura como para a escrita. Assim, na categoria regular teríamos palavras tais como faca, nada, vida e, na categoria irregular, palavras tais como: cego, gema, roça, osso, nexo, em que num mesmo estímulo acumulam-se irregularidade tipo 1 (A ou B) e irregularidade tipo 2. Nesses dois níveis de regularidade, as palavras devem ser emparelhadas em termos de freqüência de ocorrência, assim como em número de letras e estrutura silábica e devem ser palavras de classe aberta (substantivos e adjetivos). Como vimos, o contraste entre palavras regulares e irregulares de alta e baixa freqüência nos permite avaliar o funcionamento do processo lexical. Além disso, a interação entre freqüência e regularidade nos possibilita o estudo do desenvolvimento dos processos lexical e fonológico.

No entanto, o maior problema com que nos deparamos ao tentar construir tal lista de palavras é de ordem metodológica. Embora o controle de fatores como comprimento, estrutura silábica etc. seja manualmente factível, o fator freqüência exige uma investigação de grande abrangência na língua. Visando superar as limitações das listas utilizadas em Pinheiro (1994) e Capovilla e colaboradores (1998), Pinheiro (1996) apresenta um programa computadorizado para buscar, em um universo de quase dois milhões de palavras, o vocabulário de alta, média e baixa freqüência, a que estão expostas crianças da primeira à quarta série. O programa ainda apresenta duas limitações técnicas a serem superadas, qual sejam, a impossibilidade de alimentar seu banco de dados textual e a falta de lematização (contar a ocorrência a partir do radical da palavra). Porém, seus dados não sofrem viés de assunto e são adequados à pesquisa com crianças (e não apenas crianças, cf. Rothe-Neves, 2000). Esse programa constitui a melhor fonte de dados de ocorrência disponível à pesquisa do desenvolvimento de leitura e escrita no Português do Brasil ${ }^{7}$. Ainda assim, sobrevêm outras dificuldades, inerentes a esse tipo de pesquisa, pois, como na maioria das línguas, o universo de palavras de alta freqüência é limitado. Por exemplo, Pinheiro (1998) buscou no programa mencionado as palavras comuns às séries fundamentais. No que se refere às palavras de alta freqüência, a busca gerou uma lista contendo um total de 332 palavras (de três a oito letras). Excluindo-se deste universo as palavras de classe fechada, os plurais, os verbos (infinitivos e conjugados), as palavras acentuadas e os nomes próprios, terminamos com um

\footnotetext{
${ }^{7}$ Em Portugal há o Vocabulário Fundamental do Português (Universidade de Lisboa, 1987), resultado de uma pesquisa lexicográfica rigorosa; trabalho semelhante permanece inédito no Brasil.
}

conjunto muito pequeno de palavras, que não contém um número suficiente de itens para ser emparelhados com as palavras de baixa freqüência regulares e irregulares, variando em número de letras e estrutura silábica.

Diante dessa impossibilidade, somos forçados a fazer uso de listas diferentes para a prova de leitura e de escrita, cada uma variando em freqüência, regularidade, comprimento e estrutura silábica. Ambas as listas devem ser lidas e ditadas. A primeira lista testará o efeito de regularidade na leitura. Assim, as palavras seriam classificadas como regular ou irregular (tomando-se a correspondência letra-som). Na categoria regular, devemse excluir as palavras regulares para a leitura e irregulares para a escrita. Devem-se excluir também as palavras com $\mathrm{o}$ intervocálico $<\mathrm{s}>\mathrm{e}<\mathrm{r}>$ (forte e fraco). No início da alfabetização, as crianças tendem a ler /'coisa/ e não / 'coiza/, assim como a trocar o $<\mathrm{r}>$ fraco pelo forte $\mathrm{e}$ vice-versa. Com isso, espera-se contornar a possibilidade da emergência do efeito de regularidade, em decorrência da ausência de domínio pelas crianças, das correspondências letra-som unívocas, mas menos freqüentes e irregulares para a escrita. A categoria irregular seria formada de palavras do tipo 1 (A e B) e as palavras tipo $1 \mathrm{~B}$ seriam retiradas de uma tabela equivalente à Tabela 2 (palavras que favorecem erros de troca de qualidade de vogal, que evidenciam o uso da rota fonológica).

A expectativa é que o efeito de regularidade continue sendo observado na leitura de iniciantes, que predomine nas palavras de baixa freqüência, mas que se estenda aos níveis de erros cometidos. Nessa nova lista, a ausência do efeito de regularidade poderá indicar leitura lexical, mais do que na original (Pinheiro, 1994). Nesse tipo de leitura, a pronúncia das palavras não estaria, pois, sujeita a erros de troca de qualidade de vogal e regularizações. Com exceção das palavras irregulares tipo 1A, os estímulos dessa lista não devem causar nenhum problema na escrita.

A segunda lista testará o efeito de regularidade no ditado. Ao contrário da primeira lista, as palavras são classificadas do ponto de vista da correspondência somletra e as palavras regulares são desmembradas em regulares (p. ex. pala, nada, marca) e regra (p. ex. coisa, pião, carro), que testam a aquisição das regras dependentes de contexto. As palavras irregulares, serão do tipo 2 (p. ex.: onça, hora, gemido $)^{8}$.

Como cada lista será lida e escrita sob ditado, ao ler as listas que testam o efeito de regularidade na escrita, é possível que as crianças mais novas cometam erros em algumas das palavras-regra (principalmente aquelas com

\footnotetext{
${ }^{8}$ É importante notar que algumas palavras podem ser regulares (e irregulares) tanto para a leitura como para a escrita.
} 
o /s/ e /r/ intervocálicos), evidenciando assim o estágio de aquisição de regras contextuais que se encontram na leitura. Da mesma forma, esses leitores iniciantes devem apresentar um aumento de TR, ou mesmo cometer mais erros nas palavras irregulares para a escrita (mas que podem ser regulares para a leitura), por não dominarem, completamente, as relações unívocas para a leitura, tais como $<c ̧>-/ s /,<s>-/ z /$ (em final de sílaba). A despeito da possibilidade de erros contextuais nas palavras regra, é possível que esses estímulos não apresentem desvantagem significativa sobre os regulares. Porém, o contraste entre palavras regulares e irregulares pode gerar um efeito significativo, com vantagem para as palavras regulares.

Espera-se que no ditado (dessa lista com irregularidade para a escrita), o efeito de regularidade apresente as seguintes características: a) seja mais acentuado do que o observado na leitura; b) se estenda aos dois níveis de freqüência de palavras; e c) afete o desempenho de crianças mais velhas. Por exemplo, no estudo de Pinheiro (1995), para as crianças da primeira a quarta série, as palavras irregulares produziram mais erros do que as palavras regra, e estas, por sua vez, mais erros do que as palavras regulares, em ambos os níveis de freqüência. Nas séries iniciais, o efeito observado foi maior para as palavras de baixa freqüência, mas nas crianças mais velhas tornou-se semelhante nos dois níveis de freqüência, o que parece ser resultante do desenvolvimento de representações lexicais para os itens menos familiares. Com relação às palavras regra, a expectativa é que essas palavras sejam grafadas menos corretamente do que as palavras regulares, porém mais corretamente do que as palavras irregulares, pelo menos nas palavras de baixa freqüência. Pinheiro descobriu que, nas palavras de alta freqüência, o efeito de regularidade na escrita ficou restrito ao contraste entre palavras regulares e irregulares.

\section{Faz Sentido Classificar as Não-Palavras em Termos de Regularidade na Leitura?}

Iniciaremos essa discussão analisando os tipos de respostas aos estímulos não-palavras que devem ser consideradas corretas na leitura e na escrita.

\section{A - Leitura}

Normalmente, na leitura, a pronúncia de uma não-palavra é considerada correta quando ela mantém o seguinte: (1) uma correspondência letra-som permitida em dado contexto (ex.: foxe lida como /'fokse/ ou /'fofe/, ou mesmo como/'fose/ ou /'foze/); (2) um condicionamento contextual (ex.: dasa lida como /'dazə, mas não como /'dasə/); (3) o padrão correto de tonicidade da língua (ex.: puas lida como /'puəs / e não como /pu'as/) e (4) a pronúncia da vogal, como indicada pelo acento (ex.: dalé lida como "dalé" e não como "dalê").

Considerando o primeiro ponto, podemos concluir que, desde que qualquer resposta compatível com a aplicação das regras de correspondência grafema-fonema, dentro de um determinado contexto, seja considerada correta, o efeito de regularidade não é, de modo geral, esperado na leitura de não-palavras. No entanto, uma ou outra não-palavra regra, principalmente aquelas contendo o grafema $<$ s $>$ entre vogais e o ditongo nasal $<$ am $>$ ou $<$ ão $>/$ ãwN/, pode gerar erros contextuais (p. ex.: o estímulo esam lido como "essam" ou "esão" ou mesmo "essão").

Com relação às não-palavras regra, e tomando o mesmo exemplo citado no segundo ponto acima, pode ser argüido que a pronúncia de /'dasə/ ao estímulo dasa, seja uma resposta correta, desde que o sujeito produziu o som /s/ que não somente é regular, mas também o som mais freqüentemente usado para a letra $<_{\mathrm{s}}>$. No entanto, se essa classificação de erros é adotada, perdemse dados importantes sobre a aquisição das regras fonológicas da língua. Por exemplo, em Pinheiro (1994), enquanto a maioria das crianças de primeira e segunda série leram o $<\mathrm{s}>$ intervocálico de não-palavras tais como dasa, esam e foisas, como / s / e não como / z/, produzindo uma correspondência plausível mas serial, as crianças das séries mais adiantadas, ao contrário, levaram em consideração o contexto fonológico e, como resultado, leram a letra $<_{\mathrm{s}}>$ desses estímulos como $/ \mathrm{z} /$.

\section{B - Escrita}

$\mathrm{Na}$ escrita, uma não-palavra que contenha letras representando sons idênticos, em contextos idênticos, pode ser escrita de muitas maneiras diferentes. Uma resposta será considerada correta desde que o fonema com múltiplas representações seja reproduzido por um dos grafemas aceitos no contexto particular (ex.: leço /'lesw/ grafado como "lesso", "lesço", "lexo" etc, mas não como "leso" /'lezw/). Assim, todas as respostas a leço são grafias plausíveis, com exceção de "leso", que reflete um erro contextual': embora o fonema /s/ tenha

9 Pinheiro (1995), baseada em sua classificação original de erros, considerou esse tipo de erro como regularização. Nessa classificação, tanto os erros gerados de itens contendo correspondência dependente de fatores lexicais e arbitrários não explicados por regra, como os erros contextuais, eram considerados regularizações. Recentemente, no entanto, essa classificação foi desmembrada, tanto para palavras reais como para não-palavras. Os erros que refletem falta de conhecimento de regras contextuais, não mais estão sendo classificados como regularizações, mas simplesmente como erros contextuais. 
sido grafado com $<\mathrm{s}>$, a correspondência regular de /s/, o seu condicionamento contextual não foi levado em conta.

Com relação às não-palavras regra, os estímulos contendo um $<\mathrm{s}>$ intervocálico, por exemplo, são ditados com o som /z/ (como dasa, /'dazə/, esam /'ezãwN/ e foisas / foizəs/), e uma resposta é considerada correta, diferentemente da leitura, se ela for grafada tanto com a letra $<_{\mathrm{s}}>$ ou $<_{\mathrm{Z}}>$, porque na escrita, essas duas letras podem aparecer nesse contexto. Mais uma vez, no estudo de Pinheiro as crianças das séries mais adiantadas, ao contrário das crianças mais novas, tenderam a grafar esses itens com a letra $<_{\mathrm{s}}>$ ao invés da letra $<_{\mathrm{z}}>$, mostrando uma generalização da regra já citada.

A despeito dessas considerações, na escrita o exame de diferentes níveis de regularidade para as não-palavras deve gerar um efeito significativo (no estudo de Pinheiro, as nãopalavras regulares foram melhor escritas do que as nãopalavras regra e as irregulares, mas os erros dos estímulos regra não foram significativamente superiores aos erros dos estímulos irregulares). Os itens regra devem produzir erros que demostrem desconhecimento de regras contextuais bem previsíveis, o que oferecerá indicações a respeito não só do ritmo como também da ordem da aquisição dessas regras. Os itens contendo correspondências irregulares não devem causar problemas visto que qualquer grafia foneticamente plausível é considerada correta.

\section{Conclusão}

Em resumo, para sucesso do controle experimental, tratam-se as variáveis freqüência e regularidade como variáveis encaixadas para a construção de listas. Ou seja, o tempo de reação e os erros produzidos na leitura serão analisados em função de quatro categorias de estímulos: $\mathrm{BF}$ regular, BF irregular, $\mathrm{AF}$ regular e $\mathrm{AF}$ irregular. $\mathrm{Na}$ escrita, além dessas, temos mais duas categorias: $\mathrm{BF}$ regra e AF regra. Portanto, do ponto de vista operacional de construção das listas de palavras e de não-palavras isoladas a serem utilizadas num experimento, o estabelecimento dos itens em função da freqüência de ocorrência - por exemplo, a partir de Pinheiro (1996) - precede à classificação quanto à regularidade. $\mathrm{O}$ controle de ambos os fatores são imprescindíveis à análise dos resultados e à subsequente inferência sobre as propriedades do processamento estudado.

O que se pode concluir da discussão acima é que a comparação entre os erros de regularização entre palavras reais e não-palavras (mas não a comparação entre erros contextuais) tanto na leitura como na escrita, não é informativa acerca do tipo de processo que está sendo utilizado. Isso ocorre porque, enquanto as palavras reais têm sua pronúncia preestabelecida, esse não é o caso para as não-palavras. Por exemplo, a palavra boxe só pode ser corretamente lida como /'bokse/ e escrita com o grafema $\langle x>$, mas a leitura/escrita de sua não-palavra correspondente - foxe - como vimos, não é submetida a essa limitação. Em função disso, os níveis de erros de regularização sempre serão muito menores para nãopalavras do que para palavras reais. É por isso que as irregularidades da língua causam maior dificuldade para a escrita de palavras reais do que de não-palavras.

Desse modo, parece que, teoricamente, não existe nenhuma vantagem na procura do efeito de regularidade para as não-palavras. No entanto, esses estímulos devem, numa lista de teste, manter a mesma estrutura ortográfica das palavras reais. Ou seja, para efeitos de balanceamento devemos ter não-palavras regulares, regra e irregulares. Além disso, esse controle permite-nos o estudo de tendências no desenvolvimento, como ilustrado acima no caso das não-palavras-regra.

Todas essas considerações teóricas deverão ser alvo de avaliação experimental no atual estado das pesquisas do grupo de Pinheiro. Portanto, ainda estão por ser apresentados resultados que, espera-se, permitirão dissociar os efeitos de freqüência e regularidade sobre medidas de leitura e escrita e seu desenvolvimento, em crianças brasileiras.

\section{Referências}

Capovilla, A. G. S., Capovilla, F. C. \& Macedo, E. C. (1998). Validação do software CronoFonos para a análise de tempo de reação, duração e freqüência de segmentação locucionais na leitura em voz alta de itens isolados. Ciência Cognitiva: Teoria, Pesquisa e Aplicação, 2(3), 253340 .

Clark, H. H. (1973). The language-as-fixed-effect fallacy: A critique of language statistics in psychological research. Journal of Verbal Learning and Verbal Behavior, 12, 335-359.

Ellis, A. \& Young, A. W. (1988). Human cognitive neuropsychology. London: Lawrence Erlbaum.

Lecours, A. R., Delgado, A. P. \& Pimenta, M. A. M. (1993). Distúrbios adquiridos da leitura e da escrita. Em L. L. Mansur \& N. Rodrigues (Orgs.), Temas em neurolinguística (pp. 31-44). São Paulo: Tec Art.

Oliveira, M. A., Carvalho, S. E. C. \& Yoshihara, C. (2000). Palavras irregulares para a leitura: Análise de erros. Manuscrito não-publicado. Universidade Federal de Minas Gerais, Belo Horizonte, M.G., Brasil.

Parente, M. A. M. P., Hosogi, M. L. \& Lecours A. R. (1997). Conduta clínica. Em A. R. Lecours \& M. A. M. P. Parente (Orgs.), Dislexia: Implicações do sistema de escrita do português (pp. 85-105). Porto Alegre: Artes Médicas.

Parente, M. A. M. P., Silveira, A. \& Lecours A. R. (1997). As palavras do português. Em A. R. Lecours \& M. A. M. P. Parente (Orgs.), Dislexia: Implicações do sistema de escrita do Português (pp. 41-56). Porto Alegre: Artes Médicas.

Pinheiro, A. M. V. (1994). Leitura e escrita: Uma abordagem cognitiva. Campinas: Editorial Psy.

Pinheiro, A. M. V. (1995). Reading and spelling development in Brazilian Portuguese. Reading \& Writing, 7(1), 111-138. 
Pinheiro, A. M. V. (1996). Contagem de freqüência de ocorrência de palavras expostas a crianças na faixa pré-escolar e série iniciais do $1^{\circ}$ grau. São Paulo: Associação Brasileira de Dislexia.

Pinheiro, A. M. V. (1998). Avaliação cognitiva das capacidades de leitura e de escrita de crianças nas séries iniciais do $1^{\circ}$ grau. Relatório técnico-científico final a FAPEMIG (aprovado em 07/07/1999).

Pinheiro, A. M. V. \& Keys, J. K. (1987). A word count in Brazilian Portuguese. Manuscrito não publicado. Universidade de Dundee, Dundee, Escócia, UK.

Rothe-Neves, R. (2000). Processamento sintático e memória de trabalho. Em V. G. Haase, R. Rothe-Neves, C. Käppler, M. L. M. Teodoro \& G. M. O. Wood (Orgs.), Psicologia do desenvolvimento: Contribuições interdisciplinares (pp 111-120). Belo Horizonte: Health.
Sevmour, P. H. K. \& MacGregor, C. J. (1984). Developmental dyslexia: A cognitive experimental analysis of phonological, morphemic and visual impairments. Cognitive Neuropsychology, 1, 43-82.

Seymour, P. H. K. (1986). Cognitive analysis of dyslexia. London: Routledge \& Kegan Paul.

Seymour, P. H. K. (1987). Individual cognitive analysis of competent and impaired reading. British Journal of Psychology, 78, 483-506. Universidade de Lisboa /Centro de Lingüística. (1987). Português fundamental: Vocabulário e gramática. Lisboa: Instituto de Investigação Científica.

Recebido: $28 / 8 / 2000$

Revisado:1/2/2001

Aceite final: $24 / 4 / 2001$

Sobre os autores

Ângela Maria Pinheiro é Professora Titular do Departamento de Psicologia da Universidade Federal de Minas Gerais (UFMG), Mestre em Psicologia Educacional pela Universidade de Glasgow (UK), Doutora em Psicologia Cognitiva pela Universidade de Dundee (UK).

Rui Rothe-Neves é Professor do Departamento de Psicologia da Universidade Federal de Minas Gerais (UFMG), Mestre e Doutorando em Estudos Lingüísticos pela UFMG. 